\title{
Effects of ultrasound therapy on the synovial fluid proteome in a rabbit surgery-induced model of knee osteoarthritis
}

\author{
Qinglu Luo ${ }^{1,2 \dagger}$, Shuangquan $\mathrm{Ji}^{1 \dagger}{ }^{\dagger}$, Zhimi Li ${ }^{1}$, Tao Huang ${ }^{1}$, Siqin Fan² and Qin Xi ${ }^{*}$
}

*Correspondence:
137370058@qq.com
${ }^{\dagger}$ Qinglu Luo and
Shuangquan Ji contributed
equally to this work
${ }^{1}$ The Fifth Affiliated Hospital
of Guangzhou Medicine
University, No. 621, GangWan
Road, HuangPu District,
Guangzhou 510700,
Guangdong Province, China
Full list of author information
is available at the end of the
article

${ }^{*}$ Correspondence:

137370058@qq.com

Shuangquan Ji contributed equally to this work of Guangzhou Medicine

University, No. 621, GangWan Road, HuangPu District, article

\begin{abstract}
Background: Ultrasound (US) therapy may improve osteoarthritis symptoms. We investigated the effects of US on the synovial fluid (SF) proteome in a rabbit knee osteoarthritis (KOA) model to explore its therapeutic mechanisms.
\end{abstract}

Methods: Sixteen healthy 6-month-old New Zealand white rabbits (eight male, eight female), weighing $2.5-3.0 \mathrm{~kg}$, were randomly divided into groups A and B with eight rabbits per group. Both groups were subjected to right anterior cruciate ligament transaction. Six weeks after surgery, we treated the operated knee joint of group A rabbits with US and of group B rabbits with sham US for 2 weeks. The proteomes of knee joint SF from groups $A$ and $B$ rabbits were then analyzed using a label-free mass spectrometry (MS) quantification method.

Results: We identified 19 protein sequences annotated by 361 Gene Ontology (GO) items. According to the Kyoto Encyclopedia of Genes and Genomes (KEGG) database of rabbit protein sequences, we then annotated the $\mathrm{KO}$ numbers of homologous/similar proteins to 32 relevant KEGG pathways. We extracted 10 significantly differentially expressed proteins among the 32 relevant KEGG messages/metabolism pathways. The proteins whose levels were decreased were apolipoprotein A-I (AopA-1), transferrin (TF), carboxypeptidase B2 (CBP2), arylesterase/paraoxonase (PON), fibrinogen alpha chain, and alpha-2-macroglobulin (A2M). The proteins whose levels were increased were molecular chaperone HtpG/heat shock proteins (htpG, HSP90A), decorin (DCN), pyruvate kinase (PK, pyk), and fatty acid-binding protein 4/adipocyte (FABP4, aP2).

Conclusions: US therapy can alter protein levels in SF, which can decrease AopA-1, TF, CBP2, PON, fibrinogen alpha chain and A2M protein levels, and increase HtpG/HSP90A, DCN, PK/PKY, and FABP4/aP2 protein levels in SF of KOA, suggesting that the therapeutic mechanisms of US therapy on KOA may occur through changes in the SF proteome.

Keywords: Ultrasound, Proteome, Synovial membrane, Osteoarthritis, Synovial fluid

\section{Background}

Osteoarthritis (OA) is a degenerative joint disease and a common cause of musculoskeletal disability that is often characterized by progressive destruction of articular cartilage and bone changes [1]. In addition to cartilage damage, subchondral bone, synovium and synovial joint structure also show pathological changes [2]. Vina and Kwoh [3] found that sociodemographic characteristics, obesity, genetic predisposition, high bone 
density/mass diet-related factors, specific bone/joint shapes, thigh flexor muscle weakness, joint malalignment, participation in certain occupational/sports activities, and joint injury were risk factors for OA. OA patients frequently require surgical treatment and 4 million American adults underwent total knee arthroplasty, accounting for $4.2 \%$ of the population aged 50 or more. More than half of the adults diagnosed with knee OA (KOA) in the United States receive total knee replacement [4]. However, the high cost of surgery, the limited life of biological materials implanted during surgery, the reduced tolerance of elderly patients to surgery and their susceptibility to infection, postoperative rehabilitation expenses and other factors are reasons to find more economical and effective ways to treat KOA [5]. The main pathological change of OA is progressive articular cartilage degeneration; however, synovitis is another major factor in the development of OA [6, 7]. Wang et al. [8] found that synovitis was related to cartilage defects and osteophytes. Histopathological examination showed the synovial membrane to have a serious and severe inflammatory response in OA [9].

Some researchers regard synovitis as the main cause of pain and edema in OA patients [10]. In OA the synovial volume increases because the synovial membrane becomes inflamed and secretes synovial fluid (SF) containing inflammatory molecules, such as interleukins (ILs) and tumor necrosis factor (TNF) [11]. Decreasing the degree of synovitis is an important aim in OA therapy.

Currently, many physical agents [such as ultrasound (US), pulsed electromagnetic field, ultra-shortwave] are used to treat the OA $[11,12]$. However, US is superior to other physical agents, which can decrease the apoptosis of chondrocytes and delay cartilage degeneration [11]. However, the effect of US on the synovium and SF have not been documented. Some of the proteins in SF are secreted by the synovial membrane or chondrocytes or result from a diffusion process from abnormally elevated plasma levels. Therefore most studies have assayed blood markers as indicators of SF inflammation. But some inflammation markers of SF cannot diffuse into blood; therefore, direct investigation of SF should confirm the pathological change of OA.

Recently, studies of human or animal articular SF and cartilage proteomes by isobaric tags for relative and absolute quantification (iTRAQ) or mass spectrometry (MS) have been documented [13-15]. But whether US can affect the SF proteome has not been reported. We, therefore, studied the effect of US therapy on the SF proteome in a rabbit knee osteoarthritis (KOA) model.

\section{Materials and methods}

\section{Animals}

Sixteen healthy 6-month-old New Zealand white (NZW) rabbits (eight male, eight female), weighing $2.5-3.0 \mathrm{~kg}$, were recruited. All protocols were in line with national legislation and guidelines for laboratory animal care and use of the People's Republic of China Ministry of health, and were approved by the local ethics committee of Fifth Affiliated Hospital of Guangzhou Medicine University. All rabbits were killed by air embolization after the OA modeling operation and US intervention. NZW rabbits were provided by the Fujian University of Traditional Chinese Medicine animal testing center, batch number: SCXK (Shanghai) 2012-0011. 


\section{Experimental instruments and software}

The following apparatus were used. Easy-nLC Liquid Chromatograph (Thermo Scientific), Q Exactive Mass Spectrometer (Thermo Scientific), AKTA Purifier 100 (GE Healthcare), Multiscan FC Microplate Photometer (Thermo Scientific), Centrifuges (Eppendorf 5430R), Concentrator plus/Vacufuge (Eppendorf Concentrator Plus) Electrophoresis apparatus (GE Healthcare EPS601), Vertical Electrophoresis Tanks (SE260; GE-Healthcare), Thermofinnigan Easy-nLC 1000, Trap column, ASY column SC001 traps $\left(\mathrm{RP}-\mathrm{C}_{18}\right)$, Analysis column, EASY column SC200 (RP-C 18 ), Maxquant (version 1.3.0.5), Perseus (version 1.3.0.4), MP Fastprep-24 Homogenate instrument (MP Biomedicals), Ultrasonic Cell Disrupter System, Constant temperature incubator, Vortex oscillator, ProteomeDiscoverer 1.4 (Thermo Scientific), MASCOT 2.2 (Matrix Science), Perseus 1.3 (M\&M), 10 kDa Ultrafiltration centrifuge tubes, C18 Cartridge, Multiple Affinity Removal LC Column-Human 14/Mouse 3, iTRAQ Reagent-4/8plex Multiplex Kit, Dissolution buffer (AB SCIEX), SCX chromatographic column, Polysulfoethyl (PolyLCInc, Maryland, U.S.A.).

\section{Animal grouping}

Animals were randomly divided into group A (US therapy) and group B (sham US). Each group included eight rabbits.

\section{KOA model}

Animals were subjected to right knee anterior cruciate ligament transection (ACLT) as previously described [16]. Rabbits were anesthetized by intraperitoneal injection of $5 \%$ chloral hydrate $(3 \mathrm{ml} / \mathrm{kg})$. The rabbit was then fixed in the animal-fixing frame, and the right knee shaved and sterilized. A section of the medial joint was revealed. We dislocated the patella and separated and cut the anterior cruciate ligament (ACL). ACLT was ensured by Lachman testing by the surgeon, a certified veterinarian. After washing the joint with sterile saline, the incision was sealed and sterilized. After the operation the rabbits were housed in separate cages, allowed to move freely, and were routinely cared for.

\section{Intervention}

Six weeks after OA modeling, rabbits in group A were given the following US treatment: continuous mode, $1.5 \mathrm{~W} / \mathrm{cm}^{2}, 3 \mathrm{MHz}, 10 \mathrm{~min}$ per session and five times per week, for 2 weeks. The animals in group B were treated by sham US (moving the US head as for group A animals, but without turning on the machine).

\section{Label-free quantitative proteomic analysis Specimen collection}

Fourteen days after intervention, the rabbits were anesthetized with $5 \%$ chloral hydrate. SF samples $(0.5 \mathrm{ml})$ were taken from the knee joint cavity of the suprapatellar bursa, collected in an Eppendorf tube, and incubated for $5 \mathrm{~min}$ at room temperature. The solution was centrifuged by vacuum centrifugal concentration at $12,000 \times g$ for 
5 min at room temperature and the supernatant was transferred to a new tube and stored at $-80^{\circ} \mathrm{C}$ for future use.

\section{Process of measurement}

\section{Protein cleavage and quantification for a label-free experiment}

SDT buffer was added to the sample. The lysate was sonicated and then boiled for 15 min. After centrifuged at $14,000 \mathrm{~g}$ for $40 \mathrm{~min}$, the supernatant was quantified with a BCA Protein Assay Kit (Bio-Rad, USA). The sample was stored at $-80^{\circ} \mathrm{C}$.

\section{SDS-PAGE separation}

Twenty micrograms of protein from each sample were mixed with $5 \times$ loading buffer and boiled for $5 \mathrm{~min}$, centrifuged at 14,000 $\times g$ for $10 \mathrm{~min}$ and separated by $12.5 \%$ SDS-PAGE (constant current $14 \mathrm{~mA}, 90 \mathrm{~min}$ ). The protein bands were observed by Coomassie Blue R-250 staining.

\section{Filter-aided sample preparation (FASP Digestion)}

For each sample, $200 \mu \mathrm{g}$ of proteins were mixed with $30 \mu \mathrm{l}$ SDT buffer (4\% SDS, $100 \mathrm{mM}$ DTT, $150 \mathrm{mM}$ Tris-HCl pH 8.0). The detergent, DTT, and other low-molecular-weight components were removed using UA buffer ( $8 \mathrm{M}$ Urea, $150 \mathrm{mM}$ Tris- $\mathrm{HCl} \mathrm{pH} 8.0)$ by repeated ultrafiltration (Microcon units, $10 \mathrm{kD})$. Then $100 \mu$ lodoacetamide $(100 \mathrm{mM}$ iodoacetamide in UA buffer) was added to block reduced cysteine residues and the samples were incubated for $30 \mathrm{~min}$ in the dark. The filters were washed with $100 \mu \mathrm{l}$ UA buffer three times and then with $100 \mu \mathrm{l} 25 \mathrm{mM} \mathrm{NH}_{4} \mathrm{HCO}_{3}$ buffer twice. Then the protein suspensions were digested with $4 \mu \mathrm{g}$ trypsin (Promega) in $40 \mu \mathrm{l} 25 \mathrm{mM} \mathrm{NH}_{4} \mathrm{HCO}_{3}$ buffer overnight at $37{ }^{\circ} \mathrm{C}$, and finally the peptides were extracted. The peptides of each sample were desalted on C18 Cartridges [Empore ${ }^{\mathrm{TM}}$ SPE Cartridges C18 (standard density), bed I.D. $7 \mathrm{~mm}$, volume $3 \mathrm{ml}$, Sigma], concentrated by vacuum centrifugation, and reconstituted in $40 \mu \mathrm{l} 0.1 \%(\mathrm{v} / \mathrm{v})$ formic acid. The peptide content was estimated by UV light spectral density at $280 \mathrm{~nm}$ using an extinction coefficient of 1.1 for a $0.1 \%$ (g/l) solution that was calculated on the basis of the frequency of tryptophan and tyrosine in vertebrate proteins.

\section{Products of protein glycolysis analyzed by LCMS/MS}

LC-MS/MS analysis was performed on a Q Exactive mass spectrometer (Thermo Scientific) that was coupled to Easy nLC (ProxeonBiosystems, now Thermo Fisher Scientific) for $60 \mathrm{~min}$. The mass spectrometer was operated in positive ion mode. MS data was acquired using a data-dependent top 10 method dynamically choosing the most abundant precursor ions from the survey scan $(300-1800 \mathrm{~m} / \mathrm{z})$ for HCD fragmentation. Automatic gain control (AGC) target was set to $3 \mathrm{e} 6$, and maximum injection time to $10 \mathrm{~ms}$. Dynamic exclusion duration was $40.0 \mathrm{~s}$. Survey scans were acquired at a resolution of 70,000 at $\mathrm{m} / \mathrm{z} 200$, and resolution for HCD spectra was set to 17,500 at $\mathrm{m} / \mathrm{z} 200$ and isolation width was $2 \mathrm{~m} / \mathrm{z}$. Normalized collision energy was $30 \mathrm{eV}$, and the underfill ratio, which specifies the minimum percentage of the target value likely to be reached at maximum fill time was defined as $0.1 \%$. The instrument was run with peptide recognition mode enabled. 


\section{Maxquant software data analysis}

We analyzed the data using MaxQuant software version 1.3.0.5 (Max Planck Institute of Biochemistry, Martinsried, Germany) [17]. The ProteinPilot parameters are presented in Table 1.

\section{Statistics and bioinformatic analysis by Perseus software}

The database files from Maxquant were analyzed by Perseus software (version 1.3.0.4). Then Gene Ontology (GO) Annotation, KEGG Pathway Annotation, Hierarchical Clustering and protein-protein interact (PPI) Network analysis were performed using the UniProtKB database (2015.03 version) and were stored in FASTA format (201504012FBOYJZXNU.fasta). We used localized sequence software, NCBI BLAST+, to compare the identification of proteins with proteins sequences in the SwissProt Mammalian Database. The whole process of SF protein detection is summarized in Fig. 1.

Quantitated protein sequences were retrieved in batches from the UniProtKB database (2015.03 version) in FASTA format (201504012FBOYJZXNU.fasta). We used localized sequence software, NCBI BLAST + , to compare the identification of proteins with proteins sequences in the SwissProt Mammalian Database. According to the similarity principle, the functional messages of homologous proteins could be used to note the target proteins. In the study, the top 10 BLAST hits with E-value less than $1 \mathrm{e}^{-3}$ for each query sequence were retrieved and loaded into Blast2GO (Version 2.8.0) for Gene Ontology (GO) mapping and annotation. Proteins with P-values $<0.05$ and fold-change ratios $\geq 8$ or $\leq 0.3$ were considered as differentially expressed proteins, and were used for the following analysis.

Proteins do not independently execute their function but act in coordination with other proteins to accomplish biochemical reactions. Thus, the biological processes in cells can be systematically and wholly understood by pathway analysis. KEGG is one

Table 1 Maxquant software parameters

\begin{tabular}{ll}
\hline Item & Value \\
\hline Enzyme & Trypsin \\
Max missed cleavages & 2 \\
Max missed cleavages & 2 \\
Main search & $6 \mathrm{ppm}$ \\
First search & $20 \mathrm{ppm}$ \\
MS/MS tolerance & $20 \mathrm{ppm}$ \\
Fixed modifications & Carbamidomethyl (C) \\
Variable modifications & Oxidation (M), acetyl (protein N-term) \\
Database & See the project report \\
Database pattern & Reverse \\
Peptide FDR & $\leq 0.01$ \\
Protein FDR & $\leq 0.01$ \\
Time window (match between runs) & 2 min \\
Protein quantification & Razor and unique peptides were \\
& used for protein quantification \\
LFQ [8] & True \\
LFQ min. ratio count & 1 \\
\hline
\end{tabular}




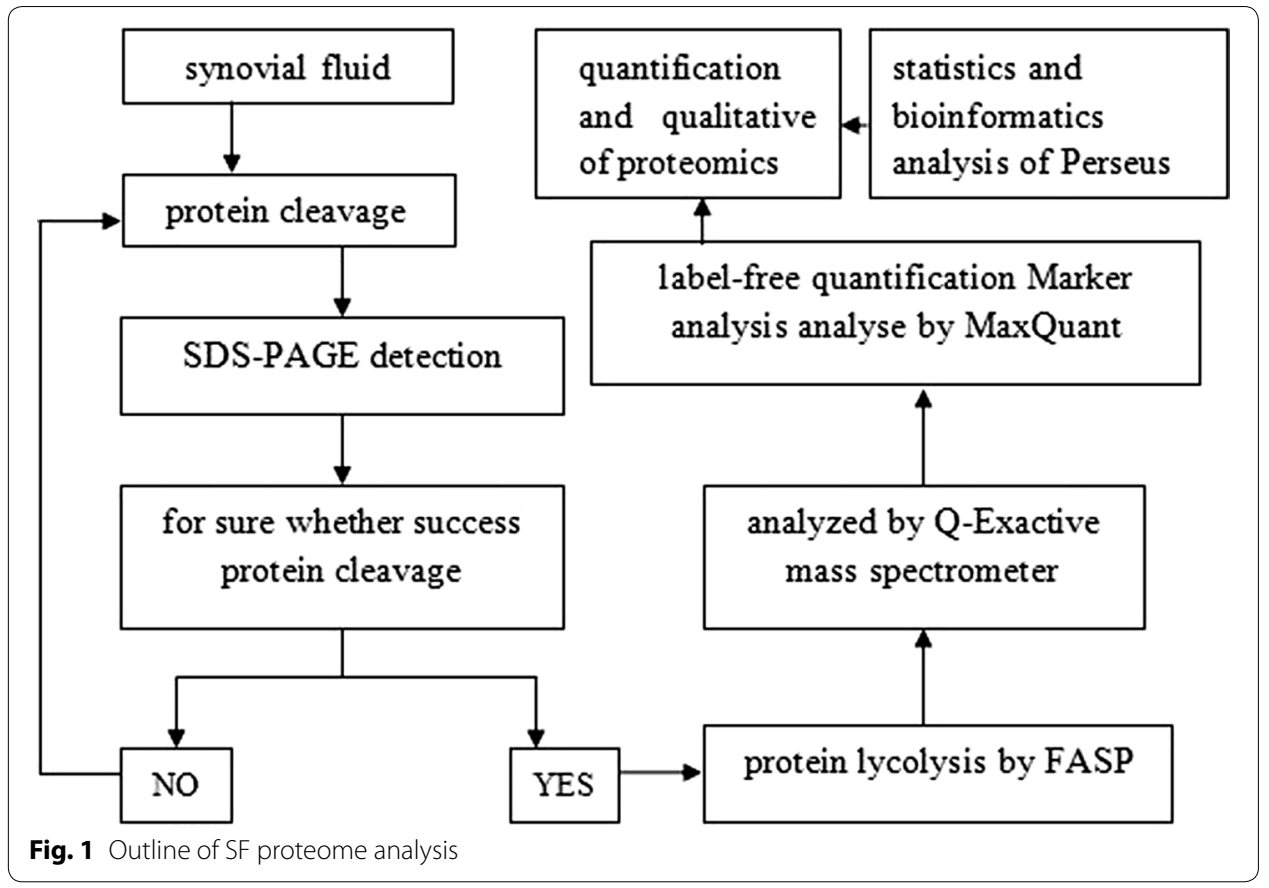

Table 2 The protein contents of samples and $O D_{280}$ contents of peptides in the US and sham US groups

\begin{tabular}{llll}
\hline Group & Volume $(\boldsymbol{\mu l})$ & Protein contents $(\boldsymbol{\mu g} / \boldsymbol{\mu l})$ & OD280 $(\boldsymbol{\mu g} / \boldsymbol{\mu l})$ \\
\hline US group & 200 & 20.72 & 1.30 \\
Sham US group & 200 & 19.67 & 1.58 \\
\hline
\end{tabular}

of the databases used to study biochemical reaction pathways. We utilized the KEGG Automatic Annotation Server to compare target protein sequences with the KEGG gene database of rabbit protein sequences and then annotated the $\mathrm{KO}$ numbers of homologous/similar proteins to the relevant KEGG pathways.

\section{Results}

The protein contents of samples and $\mathrm{OD}_{280}$ contents of peptides in groups $A$ and $B$

The protein contents of samples in the two groups are shown in Table 2. Group A was $20.72 \mu \mathrm{g} / \mu \mathrm{l}$, Group B was $19.67 \mu \mathrm{g} / \mu \mathrm{l}$.

\section{SDS-PAGE analysis}

According to the Coomassie brilliant blue atlas, the clear separation of bands of proteins in different groups indicates well extracted protein (Fig. 2).

\section{Protein glycolysis analysis by LCMS/MS in groups A and B}

We identified 244 proteins in the two groups. We confirmed 19 significantly differentially expressed proteins between the two groups. The comparable similarity range was 47-100\%; most similarity was $\geq 79 \%$ (Fig. 3). 

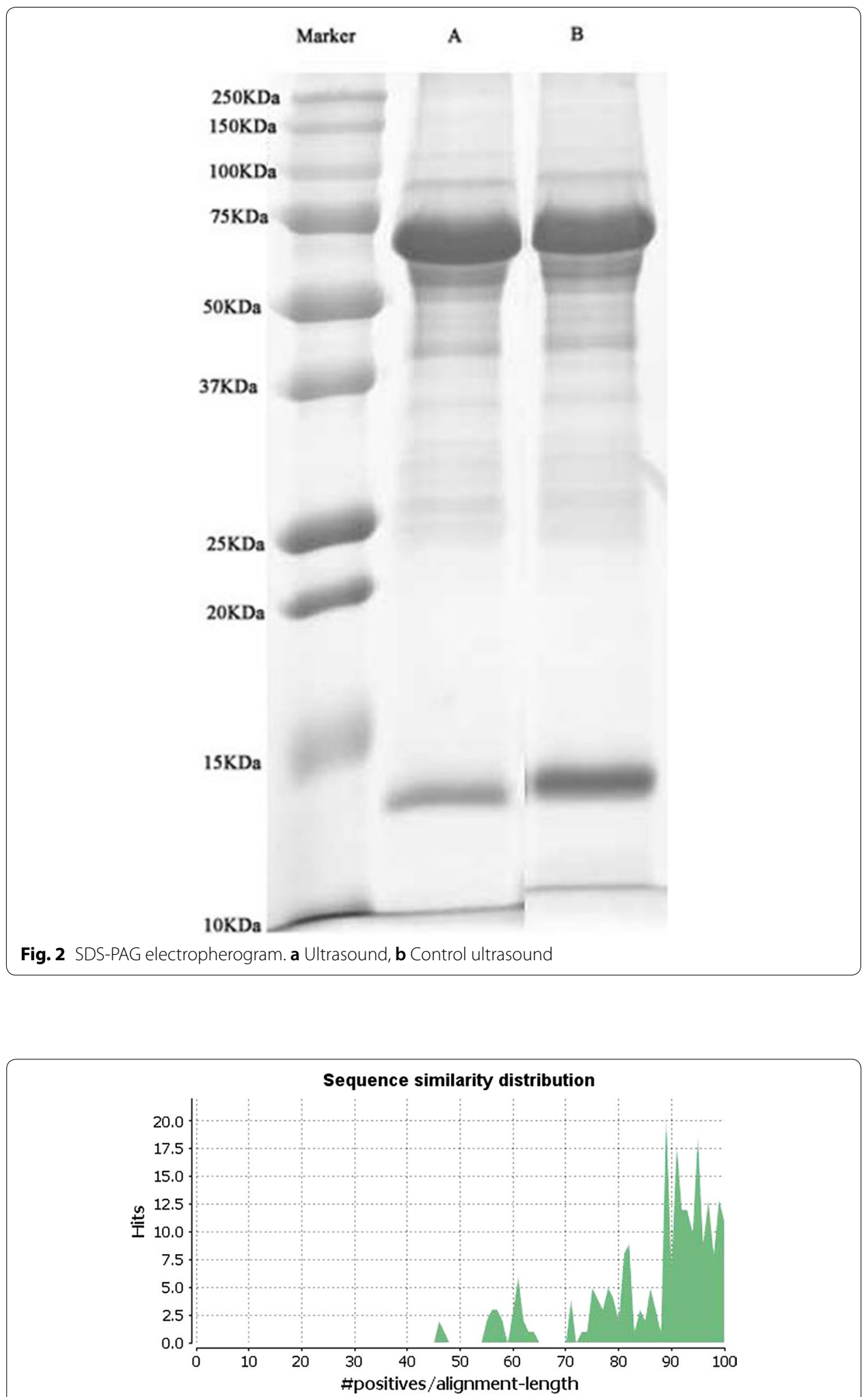

Fig. 3 The distribution of sequences with respect to similarity 

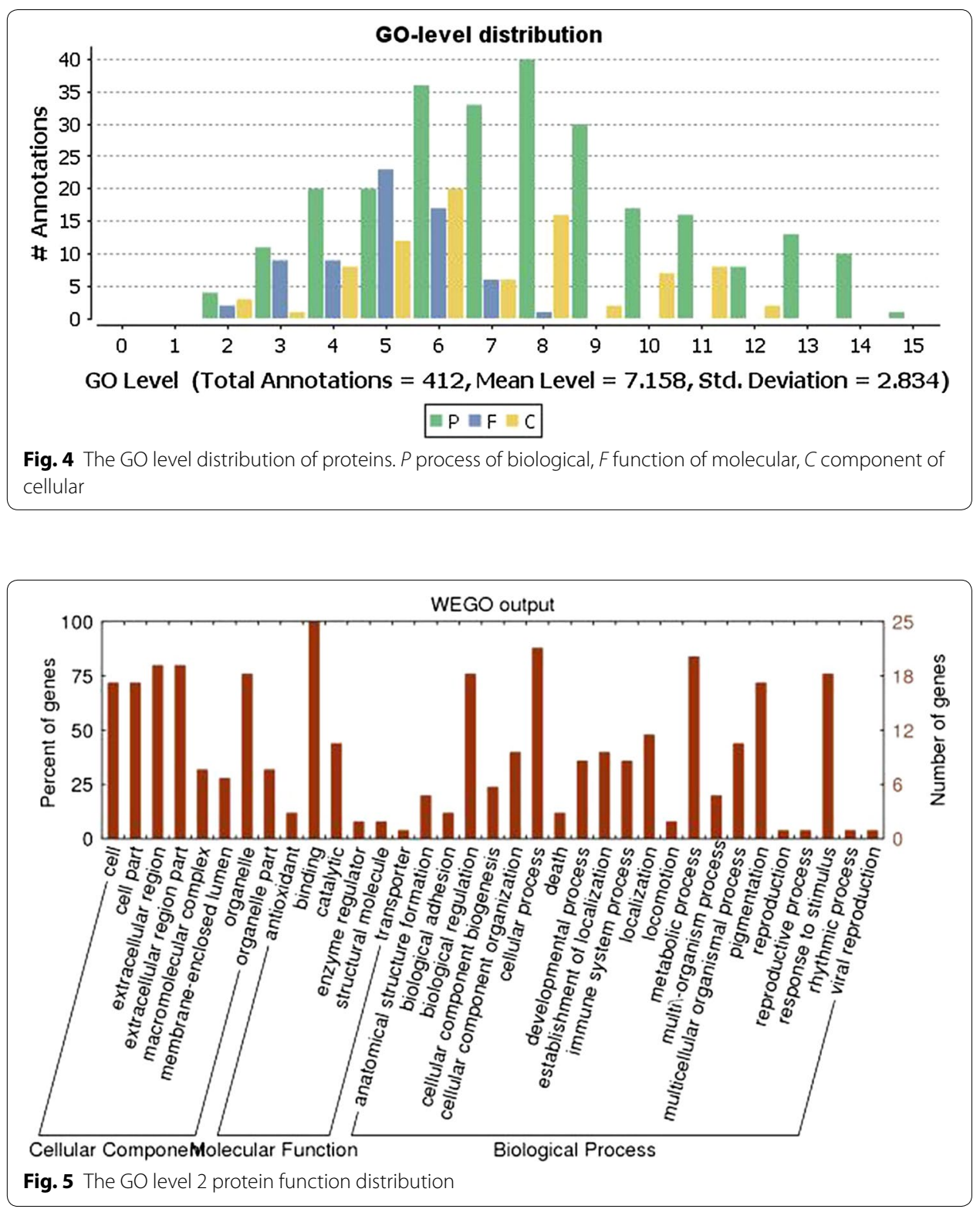

We extracted 769 relevant items in GO BlastGO2 for the 19 differentially expressed proteins. We annotated 18 proteins and $350 \mathrm{GO}$ function items; the average level of GO was 6.731 (Fig. 4).

The final annotation resulted in 19 protein sequences annotated by $361 \mathrm{GO}$ items. The GO level 2 protein function distribution is shown in Fig. 5.

We compared the target protein sequences with the KEGG database of rabbit protein sequences, then annotated the $\mathrm{KO}$ proteins of homologous/similar proteins to the relevant KEGG pathways. We extracted 10 significantly differentially expressed proteins sequences including 32 relevant KEGG messages/metabolism pathways (Table 3). All annotation pathways were saved as map files, and the significantly differentially expressed proteins were highlighted in green. Among the 10 proteins, 
Table 3 Proteins content ratios of the US and sham US groups for significantly differentially expressed proteins

\begin{tabular}{|c|c|c|c|c|c|c|}
\hline Protein ID & KO & Map ID & Pathway & Definition name & Ratio A/B & PValue \\
\hline B7NZM1 & K08757 & $\begin{array}{l}\text { ko04975 } \\
\text { ko03320 } \\
\text { ko05143 } \\
\text { ko04977 }\end{array}$ & $\begin{array}{l}\text { Fat digestion and } \\
\text { absorption } \\
\text { PPAR signaling pathway } \\
\text { African trypanosomiasis } \\
\text { Vitamin digestion and } \\
\text { absorption }\end{array}$ & apolipoprotein A-I & 0.0618 & 0.000121894 \\
\hline G1TKE4 & K14736 & $\begin{array}{l}\text { ko04066 } \\
\text { ko04978 }\end{array}$ & $\begin{array}{l}\text { HIF-1 signaling pathway } \\
\text { Mineral absorption }\end{array}$ & Transferring & 0.1773 & $1.02272 \mathrm{E}-06$ \\
\hline G1TET0 & K01300 & $\begin{array}{l}\text { ko04610 } \\
\text { ko04972 } \\
\text { ko04974 }\end{array}$ & $\begin{array}{l}\text { Complement and } \\
\text { coagulation cascades } \\
\text { Pancreatic secretion } \\
\text { Protein digestion and } \\
\text { absorption }\end{array}$ & $\begin{array}{l}\text { carboxypeptidase B2 } \\
\text { CBP2 }\end{array}$ & 0.1939 & 0.016388579 \\
\hline G1SN96 & K01045 & $\begin{array}{l}\text { ko00363 } \\
\text { ko00627 }\end{array}$ & $\begin{array}{l}\text { Bisphenol degradation } \\
\text { Aminobenzoate degra- } \\
\text { dation }\end{array}$ & $\begin{array}{l}\text { Arylesterase/paraoxo- } \\
\text { nase }\end{array}$ & 0.2037 & 0.00047988 \\
\hline G1TR31 & K03910 & ko04610 & $\begin{array}{l}\text { Complement and } \\
\text { coagulation cascades }\end{array}$ & $\begin{array}{l}\text { alpha-2-macroglobulin } \\
\text { A2M }\end{array}$ & 0.2834 & 0.001349259 \\
\hline G1T0X2 & K03903 & $\begin{array}{l}\text { ko04610 } \\
\text { ko04611 }\end{array}$ & $\begin{array}{l}\text { Complement and } \\
\text { coagulation cascades } \\
\text { Platelet activation }\end{array}$ & $\begin{array}{l}\text { fibrinogen alpha chain } \\
\text { FGA }\end{array}$ & 0.2944 & $2.2664 \mathrm{E}-05$ \\
\hline P30946 & K04079 & $\begin{array}{l}\text { ko05215 } \\
\text { ko04141 } \\
\text { ko04612 } \\
\text { ko04151 } \\
\text { ko04626 } \\
\text { ko04914 } \\
\text { ko04915 } \\
\text { ko05200 } \\
\text { ko04621 }\end{array}$ & $\begin{array}{l}\text { Prostate cancer } \\
\text { Protein processing in } \\
\text { endoplasmic reticulum } \\
\text { Antigen processing and } \\
\text { presentation } \\
\text { PI3K-Akt signaling } \\
\text { pathway } \\
\text { Plant-pathogen interac- } \\
\text { tion } \\
\text { Progesterone-mediated } \\
\text { oocyte maturation } \\
\text { Estrogen signaling } \\
\text { pathway } \\
\text { Pathways in cancer } \\
\text { NOD-like receptor signal- } \\
\text { ing pathway }\end{array}$ & $\begin{array}{l}\text { molecular chaperone } \\
\text { HtpG } \\
\text { htpG, HSP90A }\end{array}$ & 8.367 & 0.004786751 \\
\hline Q28888 & K04660 & $\begin{array}{l}\text { ko04350 } \\
\text { ko05205 }\end{array}$ & $\begin{array}{l}\text { TGF-beta signaling } \\
\text { pathway } \\
\text { Proteoglycans in cancer }\end{array}$ & $\begin{array}{l}\text { Decorin } \\
\text { DCN }\end{array}$ & 11.362 & 0.009282328 \\
\hline \multirow[t]{2}{*}{ P11974 } & K00873 & $\begin{array}{l}\text { ko00010 } \\
\text { ko00230 } \\
\text { ko00620 } \\
\text { ko01200 } \\
\text { ko01230 } \\
\text { ko04922 } \\
\text { ko04930 }\end{array}$ & $\begin{array}{l}\text { Glycolysis/Gluconeo- } \\
\text { genesis } \\
\text { Purine metabolism } \\
\text { Pyruvate metabolism } \\
\text { Carbon metabolism } \\
\text { Biosynthesis of amino } \\
\text { acids } \\
\text { Glucagon signaling } \\
\text { pathway } \\
\text { Type Il diabetes mellitus }\end{array}$ & $\begin{array}{l}\text { pyruvate kinase } \\
\text { PK, pyk }\end{array}$ & 12.006 & 0.011111008 \\
\hline & & $\begin{array}{l}\text { ko05203 } \\
\text { ko05230 }\end{array}$ & $\begin{array}{l}\text { Viral carcinogenesis } \\
\text { Central carbon metabo- } \\
\text { lism in cancer }\end{array}$ & & & \\
\hline G1T9|9 & K08753 & ko03320 & PPAR signaling pathway & $\begin{array}{l}\text { fatty acid-binding pro- } \\
\text { tein 4, adipocyte } \\
\text { FABP4, aP2 }\end{array}$ & 15.174 & $7.13941 \mathrm{E}-05$ \\
\hline
\end{tabular}


the levels of six were decreased, including apolipoprotein A-I (AopA-1), transferrin (TF), carboxypeptidase $\mathrm{B} 2$ (CBP2), arylesterase/paraoxonase (PON), fibrinogen alpha chain, and alpha-2-macroglobulin (A2M), and the levels of four were increased including molecular chaperone HtpG/heat shock proteins (htpG, HSP90A), decorin (DCN), pyruvate kinase (PK, pyk), and fatty acid-binding protein 4/adipocyte (FABP4, aP2). The results of protein content ratios and significantly differentially expressed proteins in the US and sham US groups are shown in Table 3.

\section{Discussion}

There are many rehabilitation methods for OA, and exercise therapy, with diverse exercise protocols, plays an important role in OA rehabilitation. A number of reports have indicated that physical agents can improve the range of motion and activities of daily living [18-20]. US is an effective method for the treatment of KOA [21]. US can slow down the swelling symptoms of KOA and significantly improve joint function [22, 23]. The therapeutic effect of US for OA is superior to most other physical agents [11], and its mechanisms involve diminishing inflammatory factors, which delays cartilage matrix degradation, and inhibiting chondrocyte apoptosis, which slows cartilage degeneration $[24,25]$.

With the development of proteomic technologies, it is possible to reveal the mechanisms underlying therapeutic US. There are different proteomics methods to analyze tissues. The iTRAQ method can authenticate any type of protein, and the advantages of label-free quantitation methods include no need for isotope labels as the internal standard. As previously mentioned, synovial membrane lesion is a pathological factor in OA. Whether US can alter protein expression in SF has not been reported, so we investigated the effects of US on SF proteins by a label-free method. Our results indicate that US can alter protein levels in SF (Fig. 2). These proteins have different distribution and functions, as shown in Figs. 3, 4, 5, and affect the process of KOA on multiple levels and by different pathways (see Figs. 4, 5 and Table 3). Comparing the differences in protein expression in SF between US with sham US, we identified 19 functional proteins, including 10 principal proteins that participate in 32 metabolic and transduction pathways. These results demonstrate US therapy can decrease AopA-1, TF, CBP2, PON, fibrinogen alpha chain and A2M protein levels and increase HtpG/HSP90A, DCN, PK/PKY, and FABP4/aP2 protein levels in SF of KOA.

AopA- 1 is sensitive to the level of TNF $\alpha$, and many studies have shown that TNF $\alpha$ plays a very important role in OA pathology. The regulation of cholesterol efflux may be play a critical role in OA; therefore, an LXR agonist to facilitate cholesterol efflux was considered a target for OA treatment [26]. Okabe et al. [27] showed that APOL-1 mRNA was down-regulated in patients with no sign of arthritis. They considered ApoA-1 to be a vital factor in the pathogenic mechanism of OA. We identified AopA-1 as the most significantly reduced protein in SF in our KOA model. We presume that US treatment reduced AopA-1 levels (Table 3). These results are in accordance with the report of Kong [28]. AopA-1 is the most significantly down-regulated protein in osteopenic femurs [29]. AopA-1 can affect fat digestion and absorption, vitamin digestion and absorption (Table 3); all three pathways would influence the course of OA [30-32]. 
TF/TRF transfers iron into cells, and the correlation between TF and osteoarticular diseases has been studied. Alexander et al. [33] suggested that the role of transferrin is not vital for chondrocyte survival or matrix synthesis. Chales et al. regarded arthropathy as a major and distinctive manifestation of hemochromatosis, resembling degenerative joint disease with involvement of unusual articular sites, almost identical to the arthropathy in calcium pyrophosphate dihydrate crystals deposition disease (chondrocalcinosis); early biomarkers show increasing serum transferrin saturation [34]. Huleihel et al. found IL1 can induce TRF secretion from Sertoli cells in vitro, meaning that a reduced IL1 content would depress the TRF level [35]. In this study, we found US can depress the TF protein content in SF (Table 3); therefore, we suggest US may depress the IL level in SF, thereby reducing the TRF content, because we have previously found US can decrease levels of inflammatory factors [11]. TF affects mineral absorption and the HIF-1 signaling pathway to affect the pathological process of OA [36, 37].

The thrombin/thrombomodulin complex activates $\mathrm{CPB}$. CPB acts as a procoagulant for fibrin clot formation. It can aggregate proinflammatory mediators, such as bradykinin, C5a and osteopontin. Although Song et al. [38] have shown that CPB and C5a in SF was higher in RA patients than in OA patients, CPB plays an important role in dampening local, C5a-induced inflammation and acts as a molecular link between inflammation and coagulation in OA. Christin suggested that $\mathrm{CPB}$ could prevent inflammation from destroying the joints in $\mathrm{OA}$, by reducing complement activation to some degree [39]. In short, the relationship between CPB2 and OA has not yet been defined. We identified CBP2 in the SF of KOA and after US treatment the CBP2 protein level was depressed (Table 3). CBP2 affects tissue metabolism via complement and coagulation cascades, pancreatic secretion and protein digestion and absorption pathways [40, 41].

PONs include PON1, PON2 and PON3, and they resist the oxidation of low density lipoprotein (LDL). PON1 hydrolyzes paraoxon. Some studies have indicated decreased PON1 expression after treatment of HepG2 cells with oxydic LDL, oxydic lipidosome, IL-1 $\beta$, or TNF- $\alpha$ [42]. PON1 activity declines under the environment of oxidative stress, which should result in chondrocyte telomere instability, thus the synthesis of functional glycosaminoglycan in chondrocytes is decreased [43]. Erturk et al. thought PON1 activation in serum may be an effective adjunctive marker of knee OA [44]. All of the above mentioned articles were about the relationship of serum PON to OA rather than to SF in OA. The results of this study indicate that US can decrease the PON protein level in SF (Table 3). We therefore speculate that after-treatment with US, the inflammatory reaction in the synovium is relieved, resulting in decreased PON secretion by inflammatory factors. PON affects metabolism by bisphenol degradation and aminobenzoate degradation pathways, but the relationships of bisphenol and aminobenzoate degradation metabolic pathways to OA have not been investigated.

$\mathrm{A} 2 \mathrm{M}$ is a broad-spectrum proteinase inhibitor. A2M can repress the proteolytic enzyme that functions in the process of OA [45]. Most in vitro studies have verified the relationship between A2M and OA, while the direct effects of A2M on SF have not been reported in KOA in vivo. Injection of A2M into the joint cavity can prevent the destruction of articular cartilage [46]. Wang et al. [47] also found that A2M was at insufficient levels to depress the high content of catabolic factors in OA SF; however, complementary intraarticular A2M offers chondral protection in post-traumatic OA. However, our 
results indicate US can decrease the A2M protein level in SF (Table 3). We speculate that after US treatment, synovial inflammation is reduced and the levels of anti-inflammatory cytokines are decreased by a feedback mechanism. For example, Kolarov et al. [48] demonstrated an increase in A2M in OA blood and SF as a protective reaction. A2M also affects tissue metabolism by complement and coagulation cascade pathways.

Fibrinogen is involved in hemokinesis and Kong have identified three proteins (apolipoprotein, haptoglobin precursor, and fibrinogen D fragment) that are related to joint diseases in OA SF samples by one and two dimension electrophoresis [18]. Belcaro et al. found fibrinogen levels were lowered to $62.8 \%$ of initial values after intervention in response to the anti-inflammatory substance, pycnogenol, in osteoarthritic joints [49]. Balakrishnan found that fibrinogen content was increased in rheumatic arthritis (RA) SF but not in OA SF [7]. Richette reported that fibrinogen was decreased after massive loss weight in obese patients who suffer from knee OA [50]. Our results indicate US can decrease the fibrinogen protein level in SF (Table 3). We speculate US can decrease fibrinogen levels to relieve synovium membrane inflammation. Fibrinogen affects tissue metabolism by complement and coagulation cascades and platelet activation pathways.

There are many kinds of heat shock protein according to molecular weight and homology and they include HSP90, HSP70 and HtpG/HSP90A. They act to prevent harm to organisms [51]. Apaf-1 and TNF are closely related to OA. HSP90 blocks apoptosis of cells by repressing the oligomerization of Apaf-1 [52]. HSP90 can also prevent the apoptosis induced by TNF by maintaining the receptor protein stability and interaction to enhance NF-kB activity and regulate AKT [53]. Therefore, HSPs affect the differentiation, maturation and metabolism of chondrocytes. The expression of HSP70 and aggrecan were increased in model OA rats administrated microwave radiation and intraarticular glutamine [54]. No relationship between SF and OA and HSPs was previously reported, but our results indicate that SF contains HSPs/90 and that the HSPs/90 content was increased in the US group compared with the sham US group (Table 3) so that synovial inflammation is relieved. HSPs/90 influences tissue metabolism by processing proteins involved in antigen processing and presentation, endoplasmic reticulum function, NOD-like receptor signaling, PI3K-Akt signaling, plant-pathogen interaction, progesterone-mediated oocyte maturation and estrogen signaling.

DCN is a family of small leucine rich proteoglycans; most DCNs are distributed in bone, cartilage, tendon and sclera in the extracellular matrix [55]. DCN has a feedback role on TGF- $\beta$ function which affects the synovial membrane and cartilage [56]. DCN mRNA content increases and DCN protein levels decrease in the cartilage of OA patients and with increasing age, the decomposition of DCN fragments increases [57]. These results indicate that DCN plays an important role in cartilage repair in OA patients. Our results show that the DCN protein is enhanced in SF (Table 3); therefore, US can prevent synovial damage. DCN influences metabolism via the TGF-beta signaling pathway.

PK/PYK is a key enzyme in glycolysis. There are four PK isoenzymes, LPK, RPK, M1PK and M2PK [58]. Recently, Bluemlein revealed that M2PYK is nearly always the most plentiful subtype. PKM2 catalyzes the conversion of phosphoenolpyruvate to pyruvate in the glycolysis pathway [59]. PKM2 regulates cell proliferation [60]. Oremek et al. [61] found the pyruvate kinase concentrations in plasma were increased in 
patients with rheumatic diseases, but the relationship between pyruvate kinase and OA hasn't been reported. Our results state that US can stimulate PYK protein in SF (Table 3), which would prevent synovial damage. PKY influences metabolism via glycolysis, purine metabolism, carbon metabolism, biosynthesis of amino acids, and diabetes mellitus pathways.

FABP4/aP2 belongs to a family of low-molecular-weight cytoplasmic proteins and mainly affects the PPAY- $\gamma$ pathway. Many diseases are intimately related to FABP4/ aP2 (e.g. metabolic syndrome and atherosclerosis and possibly osteoarthritis and FABP) $[62,63]$, but its involvement in SF in KOA is unknown. Our investigation found US can upregulate FABP4/aP2 protein in SF (Table 3).

\section{Conclusion}

In conclusion, our results demonstrate that US can downregulate ApoA-I, TF, CBP2, PON, A2M, and fibrinogen alpha chain levels, upregulate HtpG/HSP90A, DCN, PK/ PKY, FABP4/aP2 protein levels in SF of KOA, those proteins may serve as targets to inhibit the progress of KOA. But further investigation is needed to identify the most important metabolic pathways in SF and how US treatment of KOA affects these pathways.

\section{Abbreviations}

US: ultrasound; OA: osteoarthritis; KOA: knee osteoarthritis; SF: synovial fluid; ACLT: anterior cruciate ligament transaction; MS: mass spectrometry; iTRAQ: isobaric tags for relative and absolute quantification; GO: Gene Ontology; KEGG: Kyoto Encyclopedia of Genes and Genomes; AopA-1: apolipoprotein A-l; TF: transferring; CBP2: carboxypeptidase B2; PON: arylesterase/paraoxonase; A2M: alpha-2-macroglobulin; HSP: heat shock proteins; DCN: decorin; PK: pyk, pyruvate kinase.

\section{Authors' contributions}

QX designed the experiments. QL, SF, ZL conducted the experiments. QL, TH, SF, QX analyzed the data, and interpreted the results, QL wrote the manuscript. All authors reviewed and approved the manuscript.

\section{Author details}

${ }^{1}$ The Fifth Affiliated Hospital of Guangzhou Medicine University, No. 621, GangWan Road, HuangPu District, Guangzhou 510700, Guangdong Province, China. ${ }^{2}$ College of Rehabilitation Medicine, Fujian University of Traditional Chinese Medicine, Fuzhou 350122, Fujian, China

\section{Acknowledgements}

Not applicable.

\section{Competing interests}

The authors declare that they have no competing interests.

Availability of data and materials

The data supporting the conclusions of this article are included within the article. Any queries regarding these data may be directed to the corresponding author.

\section{Consent for publication}

Not applicable.

Ethics approval and consent to participate

All protocols were in line with national legislation and guidelines for laboratory animal care and use of the People's Republic of China Ministry of health, and were approved by the local ethics committee of Fifth Affiliated Hospital of Guangzhou Medicine University.

\section{Funding}

The study was supported by National Natural Science Foundation of China (No. 81273774).

\section{Publisher's Note}

Springer Nature remains neutral with regard to jurisdictional claims in published maps and institutional affiliations. 
Received: 20 October 2018 Accepted: 15 February 2019

Published online: 22 February 2019

\section{References}

1. Wieland HA, Michaelis M, Kirschbaum BJ, Rudolphi KA. Osteoarthritis—an untreatable disease? Nat Rev Drug Discov. 2005;4:331-44.

2. Blom $A B$, van Lent $P L$, Holthuysen $A E$, et al. Synovial lining macrophages mediate osteophyte formation during experimental osteoarthritis. Osteoarthr Cartil. 2004;12:627-35.

3. Vina ER, Kwoh CK. Epidemiology of osteoarthritis: literature update. Curr Opin Rheumatol. 2018;30:160-7.

4. Weinstein AM, Rome BN, Reichmann WM, et al. Estimating the burden of total knee replacement in the United States. J Bone Joint Surg Am. 2013;95:385-92.

5. NIH Consensus Panel. NIH Consensus Statement on total knee replacement December 8-10, 2003. J Bone Joint Surg Am. 2004;86-A:1328-35.

6. Krasnokutsky S, Attur M, Palmer G, Samuels J, Abramson SB. Current concepts in the pathogenesis of osteoarthritis. Osteoarthr Cartil. 2008;16:S1-3.

7. Hayashi D, Roemer FW, Katur A, et al. Imaging of synovitis in osteoarthritis: current status and outlook. Semin Arthritis Rheum. 2011:41:116-30.

8. Wang $X$, Jin X, Blizzard L, et al. Associations between knee effusion-synovitis and joint structural changes in patients with knee osteoarthritis. J Rheumatol. 2017:44:1644-51.

9. Goldenberg DL, Egan MS, Cohen AS. Inflammatory synovitis in degenerative joint disease. J Rheumatol. 1982:9:204-9.

10. Scanzello CR, Goldring SR. The role of synovitis in osteoarthritis pathogenesis. Bone. 2012;51:249-57.

11. Guo H, Luo Q, Zhang J, Lin H, Xia L, He C. Comparing different physical factors on serum TNF-a levels, chondrocyte apoptosis, caspase- 3 and caspase-8 expression in osteoarthritis of the knee in rabbits. Joint Bone Spine. 2011;78:604-10.

12. Iannitti T, Fistetto G, Esposito A, Rottigni V, Palmieri B. Pulsed electromagnetic field therapy for management of osteoarthritis-related pain, stiffness and physical function: clinical experience in the elderly. Clin Interv Aging. 2013;8:1289-93.

13. Ritter SY, Subbaiah R, Bebek G, et al. Proteomic analysis of synovial fluid from the osteoarthritic knee: comparison with transcriptome analyses of joint tissues. Arthritis Rheum. 2013;65:981-92.

14. Balakrishnan L, Bhattacharjee M, Ahmad S, et al. Differential proteomic analysis of synovial fluid from rheumatoid arthritis and osteoarthritis patients. Clin Proteomics. 2014;11:1.

15. Ikeda D, Ageta H, Tsuchida K, Yamada H. iTRAQ-based proteomics reveals novel biomarkers of osteoarthritis. Biomarkers. 2013;18:565-72.

16. Hongbin W, Jingyuan D, Linyun C, Yuming D. Carboxymethylated chitin reduces MMP-1 expression in rabbit ACLT osteoarthritic cartilage. Ann Rheum Dis. 2004;63:369-72.

17. Cox J, Mann M. MaxQuant enables high peptide identification rates, individualized p.p.b.-range mass accuracies and proteome-wide protein quantification. Nat Biotechnol. 2008;26:1367-72.

18. Tascioglu F, Kuzgun S, Armagan O, Ogutler G. Short-term effectiveness of ultrasound therapy in knee osteoarthritis. J Int Med Res. 2010;38:1233-42.

19. Zhang C, Xie Y, Luo X, et al. Effects of therapeutic ultrasound on pain, physical functions and safety outcomes in patients with knee osteoarthritis: a systematic review and meta-analysis. Clin Rehabil. 2016;30:960-71.

20. Eyigör S, Karapolat H, Ibisoğlu U, Durmaz B. Does transcutaneous electrical nerve stimulation or therapeutic ultrasound increase the effectiveness of exercise for knee osteoarthritis: a randomized controlled study. Agri. 2008;20:32-40.

21. Yeğin T, Altan L, Kasapoğlu Aksoy M. The effect of therapeutic ultrasound on pain and physical function in patients with knee osteoarthritis. Ultrasound Med Biol. 2017;43:187-94.

22. Jia L, Wang Y, Chen J, Chen W. Efficacy of focused low-intensity pulsed ultrasound therapy for the management of knee osteoarthritis: a randomized, double blind, placebo-controlled trial. Sci Rep. 2016;6:35453.

23. Zahoor T, Mitchell R, Bhasin P, et al. Effect of low-intensity pulsed ultrasound on joint injury and post-traumatic osteoarthritis: an animal study. Ultrasound Med Biol. 2018;44:234-42.

24. Li X, Li J, Cheng K, et al. Effect of low-intensity pulsed ultrasound on MMP-13 and MAPKs signaling pathway in rabbit knee osteoarthritis. Cell Biochem Biophys. 2011;61:427-34.

25. Gurkan I, Ranganathan A, Yang X, et al. Modification of osteoarthritis in the guinea pig with pulsed low-intensity ultrasound treatment. Osteoarthr Cartil. 2010;18:724-33.

26. Tsezou A, Iliopoulos D, Malizos KN, Simopoulou T. Impaired expression of genes regulating cholesterol efflux in human osteoarthritic chondrocytes. J Orthop Res. 2010;28:1033-9.

27. Okabe T, Ohmori Y, Tanigami A, et al. Detection of gene expression in synovium of patients with osteoarthritis using a random sequencing method. Acta Orthop. 2007;78:687-92.

28. Kong MK, Min BH, Lee PC. Evaluation of a pretreatment method for two-dimensional gel electrophoresis of synovial fluid using cartilage oligomeric matrix protein as a marker. J Microbiol Biotechnol. 2012;22:654-8.

29. Chaput CD, Dangott LJ, Rahm MD, Hitt KD, Stewart DS, Wayne Sampson H. A proteomic study of protein variation between osteopenic and age-matched control bone tissue. Exp Biol Med (Maywood). 2012;237:491-8.

30. Jingbo W, Aimin C, Qi W, Xin L, Huaining L. Betulinic acid inhibits IL-1 $\beta$-induced inflammation by activating PPAR- $\gamma$ in human osteoarthritis chondrocytes. Int Immunopharmacol. 2015;29:687-92.

31. O'Conor CJ, Griffin TM, Liedtke W, Guilak F. Increased susceptibility of Trpv4-deficient mice to obesity and obesityinduced osteoarthritis with very high-fat diet. Ann Rheum Dis. 2013;72:300-4. 
32. Misra D, Booth SL, Tolstykh I, et al. Vitamin K deficiency is associated with incident knee osteoarthritis. Am J Med. 2013;126:243-8

33. Cigan AD, Nims RJ, Albro MB, et al. Insulin, ascorbate, and glucose have a much greater influence than transferrin and selenous acid on the in vitro growth of engineered cartilage in chondrogenic media. Tissue Eng Part A. 2013;19:1941-8.

34. Chalès G, Guggenbuhl P, Pawlotsky Y. Iron overload and arthropathy. Rev Prat. 2006;56:2135-40.

35. Huleihel M, Zeyse D, Lunenfeld E, Zeyse M, Mazor M. Induction of transferrin secretion in murine Sertoli cells by FSH and IL-1: the possibility of different mechanism(s) of regulation. Am J Reprod Immunol. 2002;47:112-7.

36. Zhang FJ, Luo W, Lei GH. Role of HIF-1a and HIF-2a in osteoarthritis. Joint Bone Spine. 2015;82:144-7.

37. Karaaslan F, Mutlu M, Mermerkaya MU, Karaoğlu S, Saçmaci Ş, Kartal Ş. Comparison of bone tissue trace-element concentrations and mineral density in osteoporotic femoral neck fractures and osteoarthritis. Clin Interv Aging. 2014;9:1375-82

38. Song J, Hwang I, Cho KH, et al. Plasma carboxypeptidase B downregulates inflammatory responses in autoimmune arthritis. J Clin Invest. 2011;121:3517-27.

39. Lepus $\mathrm{CM}$, Song JJ, Wang Q, et al. Brief report: carboxypeptidase B serves as a protective mediator in osteoarthritis. Arthritis Rheumatol. 2014;66:101-6.

40. Woodman I. Osteoarthritis: carboxypeptidase B inhibits complement and cartilage loss. Nat Rev Rheumatol. 2013;9:697.

41. Kang L, Chen $\mathrm{CH}$, Wu MH, Chang JK, Chang FM, Cheng JT. 17ß-estradiol protects against glucosamine-induced pancreatic $\beta$-cell dysfunction. Menopause. 2014;21:1239-48.

42. Van Lenten BJ, Wagner AC, Navab M, Fogelman AM. Oxidized phospholipids induce changes in hepatic paraoxonase and ApoJ but not monocyte chemoattractant protein-1 via interleukin-6. J Biol Chem. 2001;276:1923-9.

43. Yudoh K, Nguyen VT, Nakamura H, Hongo-Masuko K, Kato T, Nishioka K. Potential involvement of oxidative stress in cartilage senescence and development of osteoarthritis: oxidative stress induces chondrocyte telomere instability and downregulation of chondrocyte function. Arthritis Res Ther. 2005;7:R380-91.

44. Ertürk C, Altay MA, Selek S, Koçyiğit A. Paraoxonase-1 activity and oxidative status in patients with knee osteoarthritis and their relationship with radiological and clinical parameters. Scand J Clin Lab Invest. 2012;72:433-9.

45. Luan Y, Kong L, Howell DR, et al. Inhibition of ADAMTS-7 and ADAMTS-12 degradation of cartilage oligomeric matrix protein by alpha-2-macroglobulin. Osteoarthr Cartil. 2008;16:1413-20.

46. Lin ZH, He AS, Fu M, et al. The effects of alpha2-macroglobin on the meniscus after the transaction of anterior cruciate ligament. Zhonghua Guanjie Waike Zazhi Dianziban. 2010;4:93-8.

47. Wang S, Wei X, Zhou J, et al. Identification of a2-macroglobulin as a master inhibitor of cartilage-degrading factors that attenuates the progression of posttraumatic osteoarthritis. Arthritis Rheumatol. 2014:66:1843-53.

48. Kolarov Z, Stoilov R, Baleva M, et al. Alpha-2 macroglobulin in serum and synovial fluid of patients with rheumatoid arthritis and osteoarthrosis. Ter Arkh. 2000;72:17-9.

49. Belcaro G, Cesarone MR, Errichi S, et al. Variations in C-reactive protein, plasma free radicals and fibrinogen values in patients with osteoarthritis treated with Pycnogenol. Redox Rep. 2008;13:271-6.

50. Richette P, Poitou C, Garnero P, et al. Benefits of massive weight loss on symptoms, systemic inflammation and cartilage turnover in obese patients with knee osteoarthritis. Ann Rheum Dis. 2011;70:139-44.

51. Taylor RP, Benjamin IJ. Small heat shock proteins: a new classification scheme in mammals. J Mol Cell Cardiol. 2005;38:433-44.

52. Kamradt MC, Lu M, Werner ME, et al. The small heat shock protein alpha B-crystallin is a novel inhibitor of TRAILinduced apoptosis that suppresses the activation of caspase-3. J Biol Chem. 2005;280:11059-66.

53. Lewis J, Devin A, Miller A, et al. Disruption of hsp90 function results in degradation of the death domain kinase, receptor-interacting protein (RIP), and blockage of tumor necrosis factor-induced nuclear factor-kappaB activation. J Biol Chem. 2000;275:10519-26.

54. Fujita S, Arai Y, Nakagawa S, et al. Combined microwave irradiation and intraarticular glutamine administrationinduced HSP70 expression therapy prevents cartilage degradation in a rat osteoarthritis model. J Orthop Res. 2012:30:401-7.

55. Kinsella MG, Bressler SL, Wight TN. The regulated synthesis of versican, decorin, and biglycan: extracellular matrix proteoglycans that influence cellular phenotype. Crit Rev Eukaryot Gene Expr. 2004;14:203-34.

56. Blom AB, van der Kraan PM, van den Berg WB. Cytokine targeting in osteoarthritis. Curr Drug Targets. 2007;8:283-92.

57. Melrose J, Fuller ES, Roughley PJ, et al. Fragmentation of decorin, biglycan, lumican and keratocan is elevated in degenerate human meniscus, knee and hip articular cartilages compared with age-matched macroscopically normal and control tissues. Arthritis Res Ther. 2008;10:R79.

58. Yamada K, Noguchi T. Nutrient and hormonal regulation of pyruvate kinase gene expression. Biochem J. 1999:337:1-11.

59. Bluemlein K, Grüning NM, Feichtinger RG, Lehrach H, Kofler B, Ralser M. No evidence for a shift in pyruvate kinase PKM1 to PKM2 expression during tumorigenesis. Oncotarget. 2011;2:393-400.

60. Morgan HP, O'Reilly FJ, Wear MA, et al. M2 pyruvate kinase provides a mechanism for nutrient sensing and regulation of cell proliferation. Proc Natl Acad Sci USA. 2013;110:5881-6.

61. Oremek GM, Müller R, Sapoutzis N, Wigand R. Pyruvate kinase type tumor M2 plasma levels in patients afflicted with rheumatic diseases. Anticancer Res. 2003;23:1131-4.

62. Dragojevič J, Logar DB, Komadina R, Marc J. Osteoblastogenesis and adipogenesis are higher in osteoarthritic than in osteoporotic bone tissue. Arch Med Res. 2011;42:392-7.

63. Woods A, James CG, Wang G, Dupuis H, Beier F. Control of chondrocyte gene expression by actin dynamics: a novel role of cholesterol/Ror-alpha signalling in endochondral bone growth. J Cell Mol Med. 2009;13:3497-516. 